\section{Dual mechanism of vascular endothelial growth factor upregulation by hypoxia in human hepatocellular carcinoma}

\author{
Z von Marschall, T Cramer, M Höcker, G Finkenzeller, B Wiedenmann, S Rosewicz
}

\begin{abstract}
Backgroundlaims-Vascular endothelial growth factor (VEGF) plays a key role in regulation of tumour associated angiogenesis. In the current study we analysed expression of VEGF and its receptors in human hepatocellular carcinoma (HCC) and investigated the molecular mechanisms of VEGF regulation by hypoxia. Methods-VEGF, kinase domain region (KDR)/fetal liver kinase 1 (flk-1), and flt-1 expression were examined by immunohistochemistry and in situ hybridisation in $\mathbf{1 5}$ human HCC tissues. Expression of VEGF and regulation by hypoxia were assessed in three human HCC cell lines using a quantitative competitive reverse
\end{abstract} transcription-polymerase chain reaction, ELISA, and a series of $5^{\prime}$ deletion reporter gene constructs of the human VEGF promoter in transient transfection assays. Results-We observed over expression of VEGF mRNA and protein in HCC compared with cirrhosis or normal liver. Expression of VEGF in tumour cells was strongly increased in areas directly adjacent to necrotic/hypoxic regions. Both VEGF receptors were detected in vascular endothelia of HCC while only KDR/flk-1 receptors were detected in endothelial cells of cirrhotic livers. Expression of VEGF was observed in all human HCC cell lines examined. Hypoxia ( $1 \%$ oxygen) resulted in profound upregulation of VEGF mRNA and protein levels. Furthermore, hypoxia treatment resulted in a doubling of VEGF mRNA stability. Deletion analysis of the human VEGF 5 ' flanking region -2018 and +50 demonstrated induction of VEGF promoter activity under hypoxic conditions which was significantly decreased following deletion of the region -1286 and -789 suggesting a substantial contribution of the $\mathbf{- 9 7 5}$ putative hypoxia inducible factor 1 binding site to hypoxia mediated transcriptional activation of the VEGF gene.

Conclusion-These data suggest hypoxia as a central stimulus of angiogenesis in human HCC through upregulation of VEGF gene expression by at least two distinct molecular mechanisms: activation of VEGF gene transcription and an increase in VEGF mRNA stability.

(Gut 2001;48:87-96)

Keywords: hepatocellular carcinoma; angiogenesis; vascular endothelial growth factor; hypoxia
Over the past few years experimental evidence has accumulated which indicates that growth of solid tumours and tumour metastasis are critically dependent on angiogenesis. ${ }^{1-4}$ Tumour cells induce formation of new blood vessels to supply the tumour mass with blood borne nutrients by a process termed "angiogenic switch" which is characterised by over expression of proangiogenic factors paralleled by decreased expression of antiangiogenic factors. ${ }^{34}$ Among these factors, vascular endothelial growth factor (VEGF), also known as vascular permeability factor, has been identified as one of the most potent inducers of tumour associated angiogenesis. ${ }^{5-7}$ VEGF is a secreted heparin binding homodimeric glycoprotein with a molecular weight of approximately $45 \mathrm{kDa}^{5-8}$ There are five different molecular species resulting from alternative splicing of the VEGF gene which, according to their number of amino acids, have been termed VEGF $_{121}, V \mathrm{VEF}_{145}, \mathrm{VEGF}_{165}, \mathrm{VEGF}_{189}$, and $\mathrm{VEGF}_{206}{ }^{9}{ }^{10} \mathrm{VEGF}_{165}$ is the predominant isoform secreted by a variety of normal and transformed cells whereas $\mathrm{VEGF}_{206}$ is rarely expressed $^{9}$ and $\mathrm{VEGF}_{145}$ expression appears to be restricted to the reproductive organs. ${ }^{11}$ All isoforms differ in efficiency of secretion and affinity for heparin but exert similar biological effects such as stimulation of mitogenesis, migration of vascular endothelial cells, and an increase in vascular permeability. ${ }^{9}{ }^{12}$

The biological effects of VEGF are mediated by at least two tyrosine kinase receptors, kinase domain region (KDR) and fms-like tyrosine kinase 1 (flt-1) which bind VEGF with high affinity. ${ }^{13}{ }^{14}$ Both receptors show an amino acid sequence homology of approximately $44 \%$. The murine homologue of $\mathrm{KDR}$ is known as fetal liver kinase 1 (flk-1) and shares 85\% sequence identity with human KDR. ${ }^{15}$ Both receptors are predominantly expressed in vascular endothelial cells. ${ }^{16-19}$ Binding of VEGF to its receptors causes receptor dimerisation and activation of the intrinsic kinase followed by autophosphorylation of the receptor and subsequent signal transduction. There are significant differences with respect to biological relevance between KDR/flk-1 and flt-1. KDR/

Abbreviations used in this paper: HCC, hepatocellular carcinoma; Flk-1, fetal liver kinase 1; flt-1, fms-like tyrosine kinase 1 ; HIF-1, hypoxia inducible factor $1 ; \mathrm{KDR}$, kinase domain region; VEGF, vascular endothelial growth factor; DMEM, Dulbecco's modified Eagle medium; FCS, fetal calf serum; PBS, phosphate buffered saline; RT, reverse transcription; PCR, polymerase chain reaction; DRB, 5,6-dichloro-1- $\beta-_{\mathrm{D}}$-ribofuranosylbenzimidazole. 
flk-1 but not flt-1 can mediate the mitogenic and chemotactic effects of VEGF and activate signalling pathways such as the mitogen activated protain kinases in endothelial cells. ${ }^{20} 21$

The importance of VEGF and its receptors for tumour angiogenesis is supported by several lines of evidence: (i) expression of VEGF and its receptors is elevated in several human tumours compared with normal tissues, which often correlates with higher microvessel density and a poor prognosis, ${ }^{22-25}$ and (ii) inactivation of VEGF by neutralising antibodies $^{26} 27$ or retrovirus driven expression of a dominant negative mutant of the VEGF receptor flk-1 in tumour endothelia results in dramatic inhibitory effects on tumour angiogenesis and tumour growth in vivo. ${ }^{28} 29$

Human hepatocellular carcinoma (HCC) is one of the most common neoplasms worldwide, with an estimated incidence of approximately one million new cases annually. ${ }^{30}$ Prognosis of advanced HCC remains poor despite improvements in diagnostic modalities over the past years. ${ }^{30}$ The fate of HCC patients is critically affected by multilocular development of the tumour and the presence of distant metastases. HCC is generally well known to be extensively vascularised and the occurrence of primary intrahepatic and lung metastases suggests its mainly haematogenous dissemination. Therefore, it is possible that angiogenesis plays a pivotal role during hepatocellular carcinogenesis. ${ }^{31-34}$ However, little is known of the expression pattern of the VEGF/VEGF receptor system and the physiologically relevant factors controlling VEGF gene expression in human HCC. Hence in this study we examined expression of VEGF and its receptors in human HCC and investigated the molecular mechanisms of hypoxia mediated VEGF expression in hepatocellular tumour cells.

\section{Materials and methods}

MATERIALS

The following were purchased: Dulbecco's modified Eagle medium (DMEM), RPMI 1640 medium (Gibco, Berlin, Germany); UltraCulture medium (BioWhittaker, Verviers, Belgium); fetal calf serum (FCS) (Biochrom, Berlin, Germany); DNA molecular size markers, oligo(dT) primers, Moloney murine leukaemia virus (M-MLV), and restriction enzymes (Bethesda Research Laboratories (BRL), Bethesda, Maryland, USA); Thermus aquaticus DNA polymerase (Pharmacia, Uppsala, Sweden); colorimetric Bradford protein assay (Bio Rad Laboratories, Hercules, California, USA); polyclonal rabbit anti-VEGF antibody, polyclonal rabbit anti-KDR/flk-1 antibody, and polyclonal anti-flt-1 antibody (Santa Cruz Biotechnology, Santa Cruz, California, USA); monoclonal mouse anti-CD31 (dianova, Hamburg, Germany); and RNAzol B (Wak-Chemie Medical, Bad Soden, Germany); all other chemicals and reagents were purchased from Sigma Chemical Co. (Deisenhofen, Germany). Human HCC cell lines
HuH7, SkHepG1, and HepG2 were obtained from the American Type Tissue Culture Collection (ATCC).

IMMUNOHISTOCHEMICAL ANALYSIS

Immunohistochemical analysis of surgically resected formalin fixed, paraffin embedded tissue samples was carried out using the alkaline phosphatase/antialkaline phosphatase method after pressure cooker antigen retrieval. New fuchsin was used as a developer and sections were counterstained with haemalum. A rabbit polyclonal antibody at a 1:200 dilution was used for VEGF, a rabbit polyclonal antibody at a 1:100 dilution for $\mathrm{KDR} / \mathrm{flk}-1$, a rabbit polyclonal antibody at a 1:200 dilution for flt- 1 , and a mouse monoclonal antibody at a 1:100 dilution for CD31. Two independent approaches were used to confirm the specificity of the observed immunohistochemical signal: (i) serial dilution of the primary antibody until the signal disappeared; and (ii) preimmune rabbit IgG as first antibody which failed to reveal relevant staining. Slides were analysed independently by two observers.

IN SITU HYBRIDISATION

Sense and antisense ${ }^{35} \mathrm{~S}$-cRNA probes were prepared from human cDNAs subcloned into pBluescript KS vectors: a 517 bp fragment of

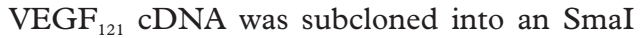
site; a 1080 bp fragment of flt-1 cDNA was subcloned into Sall and NotI sites; and a 1400 bp fragment of KDR was subcloned into a BamIII site. VEGF sense probes were generated by $\mathrm{T} 7$ polymerase following digestion with EcoRI, and antisense probes were obtained by T3 polymerase after BamHI digestion. Sense and antisense KDR cRNA probes were obtained from Xba I and EcoRI restricted templates using $\mathrm{T} 3$ and $\mathrm{T} 7$ polymerases, respectively. Sense and antisense flt- 1 cRNA probes were obtained from Sall and Not I restricted templates. In vitro transcribed cRNAs were labelled with $\left[{ }^{35}\right.$ S]UTP (1250 $\mathrm{Ci} / \mathrm{mmol}$; New England Nuclear, Boston, Massachusetts, USA). Specific activity routinely obtained was $1.2 \times 10^{9}$ to $1.4 \times 10^{9} \mathrm{cpm} / \mu \mathrm{g}$ as measured by liquid scintillation counting. Prehybridisation, hybridisation, washing procedures, and RNase digestion of mismatched sequences as well as autoradiography were performed as described previously. ${ }^{35}$ In brief, sections were treated with $0.2 \mathrm{M} \mathrm{HCl}$, digested with pronase, and fixed in $4 \%$ paraformaldehyde/phosphate buffered saline (PBS). Slides were acetylated, rinsed again in PBS, dehydrated in graded ethanols, and air dried prior to hybridisation. Hybridisation was performed for 18 hours at $52^{\circ} \mathrm{C}$ using $5 \times 10^{5}$ cpm of $\left[{ }^{35} \mathrm{~S}\right]$ labelled RNA probe. Slides were washed for five hours at $54^{\circ} \mathrm{C}$ in modified hybridisation buffer and subjected to a brief RNase A digestion. Following further washing steps, slides were dehydrated in graded ethanols, air dried, and dipped in Amersham LM1 emulsion (Amersham, Braunschweig, Germany). After exposure for $14-21$ days at $4^{\circ} \mathrm{C}$, slides were developed in Kodak D19 developer (Kodak, Hemel Hampstead, UK) for three 
minutes, rinsed in $1 \%$ acetic acid, and fixed in Kodak fixer for three minutes. After extensive washing, slides were finally counterstained in haematoxylin-eosin and mounted in Corbitt balsam.

\section{CELL CULTURE}

All HCC cell lines were grown as subconfluent monolayer cultures either in DMEM supplemented with $10 \%$ FCS (v/v; HepG-2, SkHepG1) or in RPMI 1640 supplemented with $20 \%$ (v/v; HuH7) FCS, penicillin (100 $\mathrm{u} / \mathrm{ml})$, and streptomycin $(100 \mu \mathrm{g} / \mathrm{ml})$. Cells were kept under $95 \%$ air and $5 \% \mathrm{CO}_{2}$ at $37^{\circ} \mathrm{C}$.

MEASUREMENT OF VEGF IN CELL CULTURES

For generation of conditioned media, $5 \times 10^{4}$ HuH7, SkHepG1, and HepG2 cells were plated in 12 well plates in growth medium overnight. After washing with PBS, cells were switched to serum free UltraCulture medium. Conditioned medium was collected after 16 hours of normoxic or hypoxic incubation, centrifuged to remove floating cells, and stored frozen at $-20^{\circ} \mathrm{C}$. Cells were lysed by lysis buffer ( $2 \mathrm{mM}$ EDTA, $20 \mathrm{mM}$ Tris (pH 7.8), $150 \mathrm{mM} \mathrm{NaCl}, 50 \mathrm{mM} \beta$-glycerol phosphate, $0.5 \%$ NP40, $1 \%$ glycerine, $1 \mathrm{mM}$ sodium orthovanadate, $1 \mathrm{mM}$ dithiothreitol, $5 \mu \mathrm{g} / \mathrm{ml}$ aprotinin, $10 \mathrm{mM}$ sodium fluoride, $2 \mu \mathrm{M}$ leupeptin, and $2 \mathrm{mM}$ phenylmethyl sulphonyl fluoride). Extracts were centrifuged at 15000 $\mathrm{rpm}$ for 15 minutes, and protein concentration in each supernatant was determined by colorimetric Bradford protein assay. VEGF concentrations were assessed by a commercial human VEGF specific ELISA (Quantikine, R\&D Systems) following the manufacturer's instructions, and normalised to protein content.

TRANSIENT TRANSFECTION EXPERIMENTS

HepG2 cells were transfected with $1.5 \mu \mathrm{g}$ of VEGF-luciferase reporter constructs containing different lengths of the 5 ' flanking region of the human VEGF gene promoter coupled to the promoterless luciferase reporter vector $\mathrm{pAH}$ 1409 (the various luciferase constructs are shown schematically in fig 7) and $1.5 \mu \mathrm{g}$ of the $\beta$-galactosidase expression vector $\beta-\mathrm{Gal}$. Transient transfection assays were performed using the calcium phosphate-DNA precipitation method with the calcium phosphate mammalian cell transfection kit (5 Prime $\rightarrow 3$ Prime, Inc., Boulder, USA) following the manufacturer's instructions. In brief, $2 \times 10^{5}$ cells were plated in six well dishes for 24 hours. Prior to transfection, cells were changed to fresh culture medium and incubated with calcium phosphate-DNA precipitate for six hours. After washing with PBS, cells were switched to UltraCulture medium and allowed to recover for 24 hours in a 5\% $\mathrm{CO}_{2}-95 \%$ air incubator at $37^{\circ} \mathrm{C}$. Cells were then switched to fresh UltraCulture medium and one of the two triplicate dishes from each transfection was transferred to a modular incubator (Nuaire IR Auoflow; Zapf, Sarsteedt, Germany) which was flushed with $1 \% \mathrm{O}_{2}-5 \% \mathrm{CO}_{2}-94 \% \mathrm{~N}_{2}$ and incubated for 16 hours. Cell extracts were prepared using reporter lysis buffer (Promega) and measured for luciferase and $\beta$-galactosidase activity. $\beta$-Galactosidase activity was determined by hydrolysis of $o$-nitrophenyl $-\beta_{-}{ }_{\mathrm{D}}-$ galactopyranoside (Promega) using $50 \mu \mathrm{l}$ of cell extract at $37^{\circ} \mathrm{C}$ for two hours, as measured by $\mathrm{A}_{405}$. Luciferase activity was determined using $50 \mu \mathrm{l}$ of cell extract. The reaction was initiated by injection of $100 \mu \mathrm{l}$ of luciferase assay substrate (Promega). Light production was measured for 15 seconds using a Lumat LB 9501 (EG\&G Berthold, Bad Wildbad, Germany), and results were expressed as relative light units. Relative luciferase activity was calculated as Luc (relative light units per $50 \mu \mathrm{l}$ cell extract) $/ \beta-G a l\left(\mathrm{~A}_{405}\right.$ per $50 \mu \mathrm{l}$ cell extract per two hours).

\section{REVERSE TRANSCRIPTASE}

Total RNA was isolated using the RNAzol kit following the manufacturer's instructions. Reverse transcription (RT) of RNA from hepatocellular tumour cell lines was performed using $2 \mu \mathrm{g}$ of total RNA, $25 \mathrm{ng}$ of oligo(dT) primer,

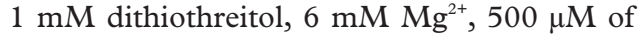
each deoxynucleoside triphosphate, 20 units of RNAsin, and 5 units of Moloney murine leukaemia virus reverse transcriptase.

POLYMERASE CHAIN REACTION (PCR) FOR VEGF SPLICE FORMS

Each RT product $(5 \mu \mathrm{l})$ was amplified by polymerase chain reaction (PCR). For amplification of VEGF a sense primer (5'-CGAAGTGGTGAAGTTCATGGATG-3') and an antisense primer (5'-TTCTGTATC AGTCTTTCCTGGT-3') were generated according to published sequences. ${ }^{31}$ These primers recognise all known VEGF splice variants. cDNAs were amplified by 1 unit of Taq-DNAPolymerase in a $20 \mu \mathrm{l}$ reaction mixture containing $10 \mathrm{mM}$ Tris $\mathrm{HCl}(\mathrm{pH} 8.3), 50 \mathrm{mM}$ $\mathrm{KCl}, 1.5 \mathrm{mM} \mathrm{MgCl}_{2}, 200 \mu \mathrm{M}$ of each deoxynucleoside triphosphate, and $40 \mathrm{pM}$ of each primer. Amplification conditions for 40 cycles were as follows: denaturation at $94^{\circ} \mathrm{C}$ for one minute, annealing at $60^{\circ} \mathrm{C}$ for one minute, extension at $72^{\circ} \mathrm{C}$ for one minute, and finally a 10 minute extension at $72^{\circ} \mathrm{C}$. For each experimental condition, one RNA aliquot was amplified without having been subjected to the RT reaction. Each PCR reaction product $(5 \mu \mathrm{l})$ was run on a $1 \%$ agarose gel and visualised using ethidium bromide.

PCR FOR VEGF 165 AND $\beta$-ACTIN

For amplification of $\beta$-actin and $\operatorname{VEGF}_{165}$, primer sequences were chosen using the commercial PcGene software package (Intelligentics, Geneva, Switzerland) on published cDNA sequences retrieved via the internet from the GeneBank database. The acceptable primer length was 20-24 bp and primers contained comparable GC contents, usually in the range $45-60 \%$. The resulting PCR products were chosen to span at least two exons and the antisense primer had to be within the first 1000 bp upstream of the polyadenylation site. Selected primer sequences are given in table 1. cDNAs were amplified by 1 unit of Taq-DNAPolymerase in a $50 \mu \mathrm{l}$ reaction mixture containing $10 \mathrm{mM}$ Tris $\mathrm{HCl}(\mathrm{pH} 8.3), 50 \mathrm{mM}$ 
Table 1 Primer sequences used for quantitative competitive reverse transcription-polymerase chain reaction (RT-PCR)

\begin{tabular}{lll}
\hline Gene & Primer $\left(5^{\prime} \rightarrow 3^{\prime}\right)$ & Location \\
\hline$\beta$-actin & Sense: TTCCTGGGCATGGAGTCCTGTGG & 837 to 859 \\
& Antisense: CGCCTAGAAGCATTTGCGGTGG & 1151 to 1172 \\
VEGF $_{165}$ & Mimic: TACCCTGGCATTGCCGACAGG & 957 to 977 \\
& Sense: GCAAGACAAGAAAATCCCTGTGGG & 465 to 488 \\
& Antisense: TTCTGTCGATGGTGATGGTGTGG & 735 to 757 \\
& Mimic: ATCCGCAGACGTGTAAATGTTCC & 525 to 548 \\
\hline
\end{tabular}

$\mathrm{KCl}, 1.5 \mathrm{mM} \mathrm{MgCl}_{2}, 0.2 \mathrm{mM}$ of each deoxynucleoside triphosphate, and $40 \mathrm{pM}$ of each primer. Amplification conditions for 30 cycles were as follows: denaturation at $94^{\circ} \mathrm{C}$ for 40 seconds, annealing at $63^{\circ} \mathrm{C}$ for one minute, extension at $72^{\circ} \mathrm{C}$ for one minute, and finally a seven minute extension at $72^{\circ} \mathrm{C}$. PCR reactions were carried out in a total volume of $50 \mu \mathrm{l}$ for 30 cycles. One quarter of the PCR reaction products were run on a $2 \%$ agarose gel and visualised using ethidium bromide.

QUANTITATIVE COMPETITIVE RT-PCR

Quantitative competitive RT-PCR is based on coamplification of a known amount of an artificial DNA (so called competitor) with different amounts of cDNA. If the amplification efficiencies of the competitor and the original PCR template are equal, it is possible to determine the cDNA concentration of a specific PCR template by measuring the ratio of competitor and wild-type PCR products. Competitors were constructed using a "semi nested" PCR technique as previously described..$^{36}$ Wild-type PCR products were reamplified using combined (so called mimic) sense primers, which bind $80-120$ bp downstream of the original sense primer but contain the original sense primer sequence at their 5 ' ends (used primer sequences are given in table 1). This results in $10-29 \%$ shorter amplicons than the wild-type PCR products that contain the same primer binding sequences at their ends. These

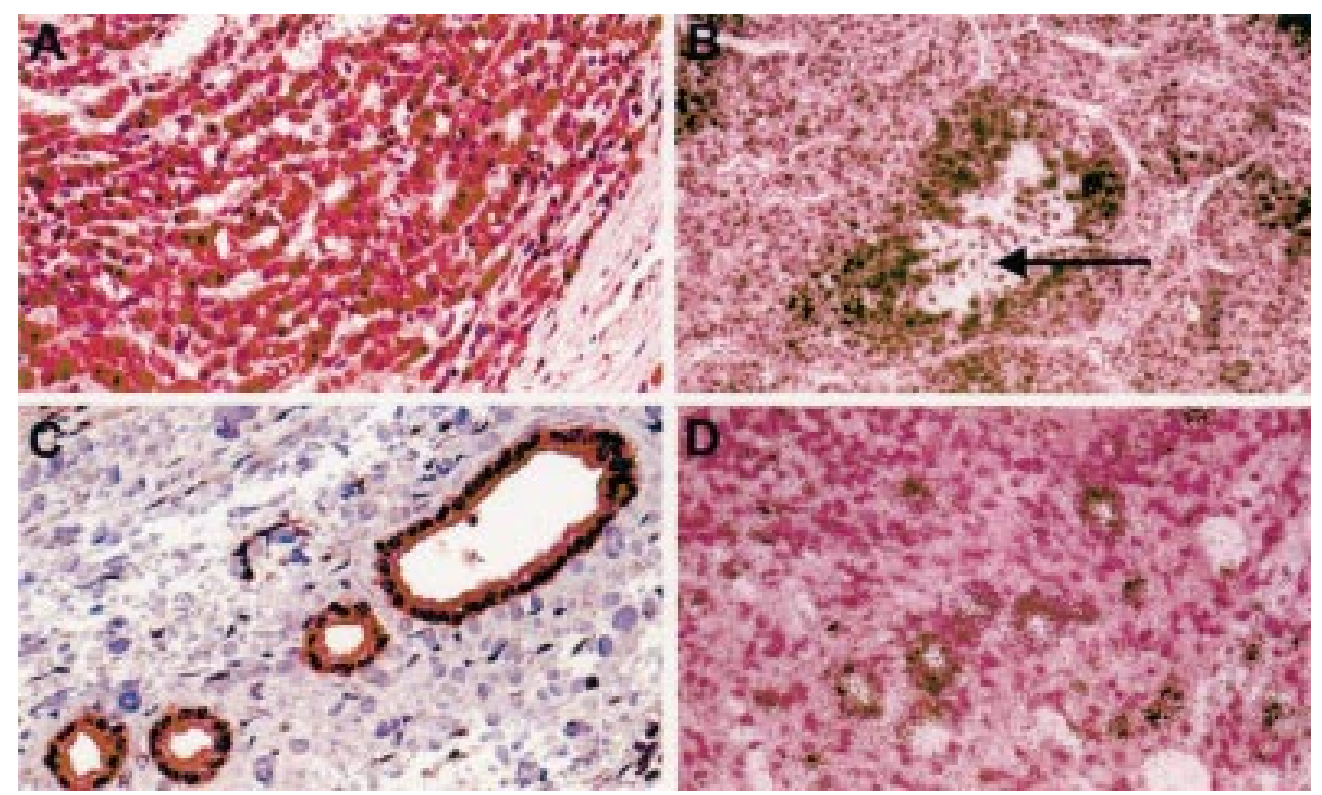

Figure 1 Expression of vascular endothelial growth factor (VEGF) in human hepatocellular carcinoma (HCC). Immunostaining with polyclonal VEGF antibody $(A, C)$ and in situ hybridisation with ${ }^{35} S$ labelled antisense cRNA for $\operatorname{VEGF}(B, D)$. VEGF was expressed by HCC cells $(A, B)$ and epithelial cells of bile ducts $(C, D)$. Exposure time for autoradiography was 14 days. The arrow indicates necrosis. Original magnification: $A, C$, and $D \times 40 ; B \times 20$. competitor constructs were purified by agarose gel electrophoresis followed by gel extraction using the commercial Qiaquick gel extraction kit (Qiagen, Santa Clarita, USA). Concentrations of the competitors were measured by densitometry of the ethidium bromide stained agarose gels. Equal amplification efficiencies for each competitor and the corresponding wild-type PCR product were verified by reamplification of different diluted mixtures of both PCR products. Only competitor constructs showing equal wild-type/competitor ratios before and after reamplification were used further for competitive PCR. For quantitative PCR, five serial 1:3 dilutions of cDNA derived from one RT were coamplified with fixed amounts of one of the different competitors. The optimal amount for each competitor construct was established in initial pilot experiments. After amplification, wild-type and competitor PCR products were separated in $2 \%$ agarose gels and stained with ethidium bromide. Digital images of the stained gel were taken using the Quick-Store-plus-ii system (MS Laborgeräte, Heidelberg, Germany) with an integrated UV light tray and CCD camera. Densitometry of PCR products was performed using the ScionImage software package (Scion Corporation, Frederick, Maryland, USA). The logarithm of the density ratios (wild-type/competitor) was plotted against the logarithm of cDNA dilution. At the competition equivalence point (log (density ratio) $=0$ ), the initial target $\mathrm{cDNA}$ is diluted to the concentration $(w / v)$ of competitor added. This allows calculation of the molar concentration of the target wild-type PCR product in cDNA. Expression of the VEGF sequence was normalised to expression of the $\beta$-actin message in the same cDNA sample. 
Table 2 Expression of vascular endothelial growth factor (VEGF) and its receptors kinase domain region (KDR)/ fetal liver kinase 1 ( $\mathrm{flk}-1$ ) and fms-like tyrosine kinase 1 (Flt-1) in human hepatocellular carcinomas assayed by in situ hybridisation

\begin{tabular}{|c|c|c|c|c|c|c|}
\hline \multirow[b]{2}{*}{ Sample } & \multicolumn{2}{|l|}{$V E G F$} & \multicolumn{2}{|c|}{$K D R / f l k-1$} & \multicolumn{2}{|l|}{ Flt-1 } \\
\hline & $\begin{array}{l}\text { Cirrhosis } \\
(11 / 15)\end{array}$ & $\begin{array}{l}\text { Tumour } \\
(13 / 15)\end{array}$ & $\begin{array}{l}\text { Cirrhosis } \\
(6 / 15)\end{array}$ & $\begin{array}{l}\text { Tumour } \\
(13 / 15)\end{array}$ & $\begin{array}{l}\text { Cirrhosis } \\
(0 / 15)\end{array}$ & $\begin{array}{l}\text { Tumour } \\
(8 / 15)\end{array}$ \\
\hline 1 & + & + & + & + & - & + \\
\hline 2 & + & + & - & - & - & - \\
\hline 3 & + & + & - & + & - & + \\
\hline 4 & - & + & - & + & - & + \\
\hline 5 & + & + & + & + & - & + \\
\hline 6 & - & + & - & + & - & + \\
\hline 7 & + & + & + & + & - & - \\
\hline 8 & + & + & - & + & - & - \\
\hline 9 & + & + & - & - & - & - \\
\hline 10 & + & + & - & + & - & + \\
\hline 11 & + & + & + & + & - & - \\
\hline 12 & + & + & + & + & - & + \\
\hline 13 & + & + & + & + & - & - \\
\hline 14 & - & - & - & + & - & - \\
\hline 15 & - & - & - & + & - & 8 \\
\hline
\end{tabular}

+ , positive hybridisation signal; -, negative hybridisation signal.

MEASUREMENT OF VEGF MRNA HALF LIFE

The half life of $\mathrm{VEGF}_{165}$ mRNA was determined after treating HepG2 cells with $150 \mu \mathrm{M}$ 5,6-dichloro-1- $\beta{ }_{-}{ }_{D}$-ribofuranosylbenzimidazole (DRB). HepG2 cells were grown in $100 \mathrm{~mm}$ dishes under normoxic $\left(21 \% \mathrm{O}_{2}\right)$ or hypoxic $\left(1 \% \mathrm{O}_{2}\right)$ conditions in serum free UltraCulture medium for 16 hours prior to addition of DRB to block transcription. Immediately after addi-
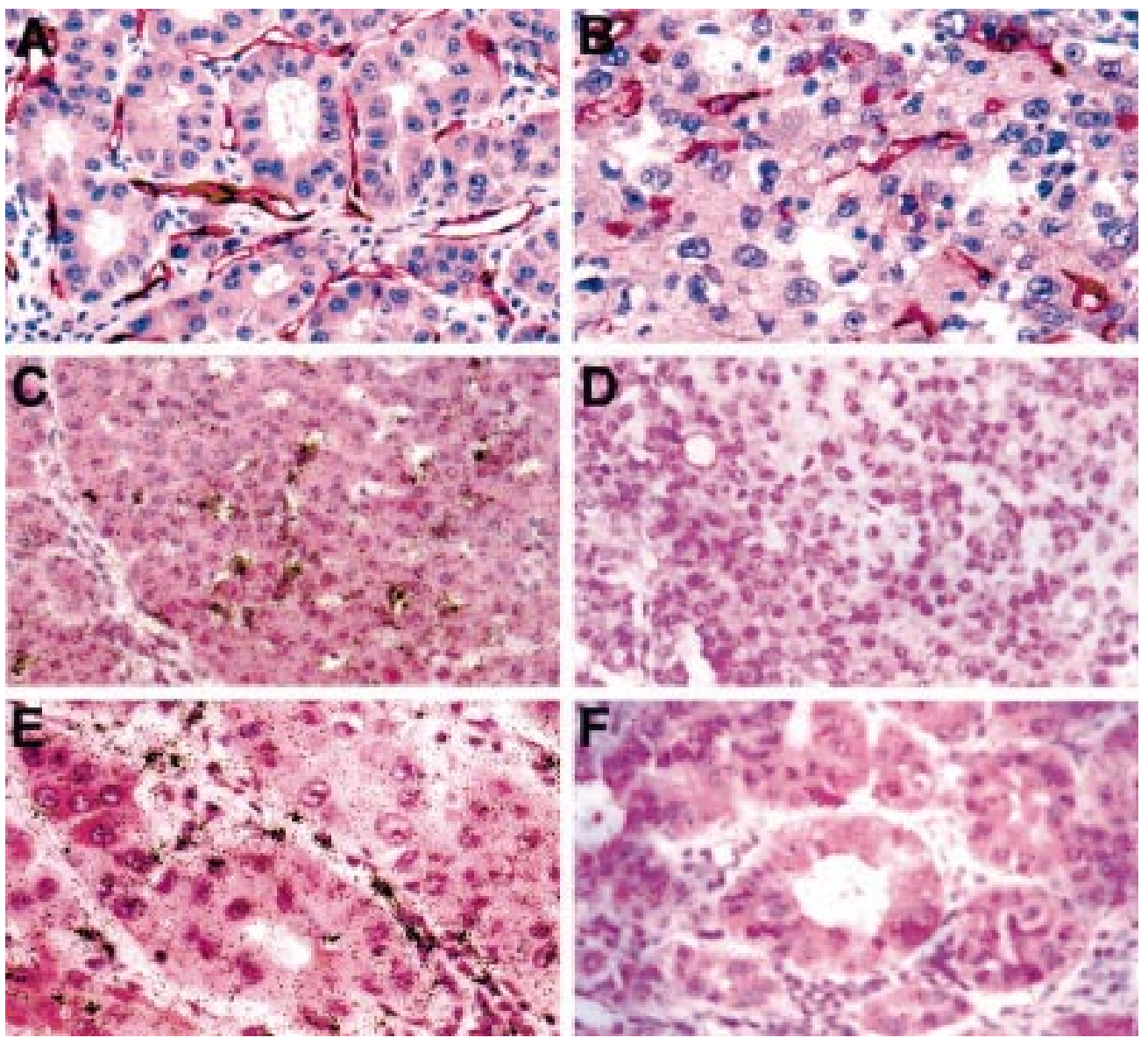

Figure 2 Expression of vascular endothelial growth factor (VEGF) receptors kinase domain region (KDR) /fetal liver kinase 1 (flk-1) and fms-like tyrosine kinase 1 (flt-1) in human hepatocellular carcinoma (HCC). Immunostaining with anti-CD31 antibody $(A)$ and anti-flt-1 (B). In situ hybridisation with ${ }^{35} S$ labelled antisense $c R N A$ for $f t-1(C)$ and KDR/fk-1 $(E)$ or sense probes, respectively $(D, F)$. Flt-1 $(B, C)$ and KDR/flk-1 $(E)$ expression was observed exclusively in endothelial cells of HCC tissue. Hybridisation with sense cRNAs for flt-1 (D) and KDR/flk-1 (F) did not reveal any significant hybridisation signal. Exposure time for autoradiography was 14 days. Original magnification: $A, B, E$, and $F$ $\times 40 ; C$ and $D \times 20$

tion of DRB, cells were returned to the same culture conditions (normoxia or hypoxia) and harvested for RNA after $0,0.5,1,2,3,4$, and 6 hours. Total RNA was isolated using the RNazol kit following the manufacturer's instructions. The amount of $\mathrm{VEGF}_{165}$ mRNA was determined using RT competitive PCR as described above. The experiment was repeated three times. The half life of $\mathrm{VEGF}_{165}$ mRNA was calculated by drawing the best fit linear curve on a log linear plot of VEGF mRNA (\% of normoxic controls) versus time.

STATISTICAL ANALYSIS

Statistical differences were evaluated by one way analysis of variance (ANOVA). Statistical analyses were performed using GraphPad statistical software (San Diego, California, USA). Differences were considered statistically different if $\mathrm{p}<0.05$.

\section{Results}

EXPRESSION OF VEGF IN HUMAN HCC AND LIVER CIRRHOSIS

using a ${ }^{35} \mathrm{~S}$ labelled cRNA probe encoding for human $\mathrm{VEGF}_{121}$, we analysed 15 surgically resected human HCCs that contained adjacent cirrhotic liver tissue as well as two normal human liver specimens. We observed a strong
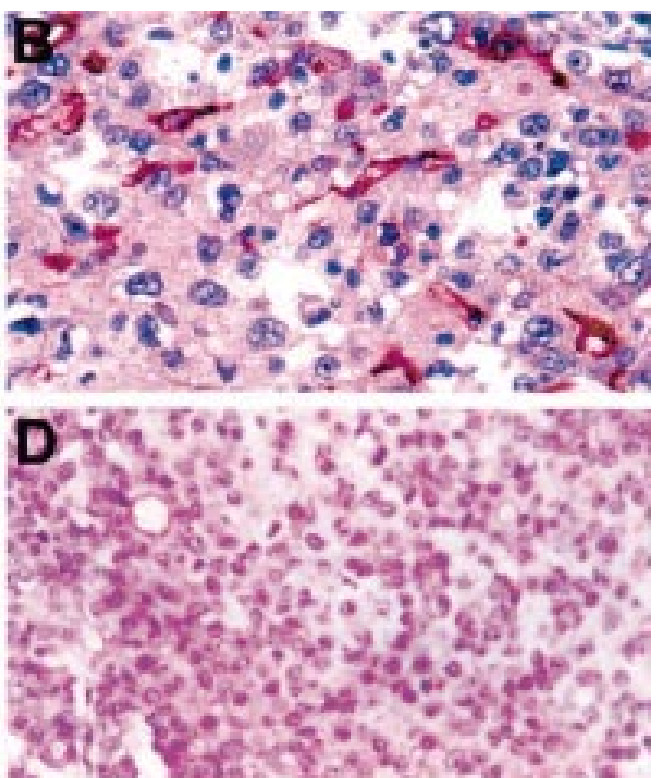

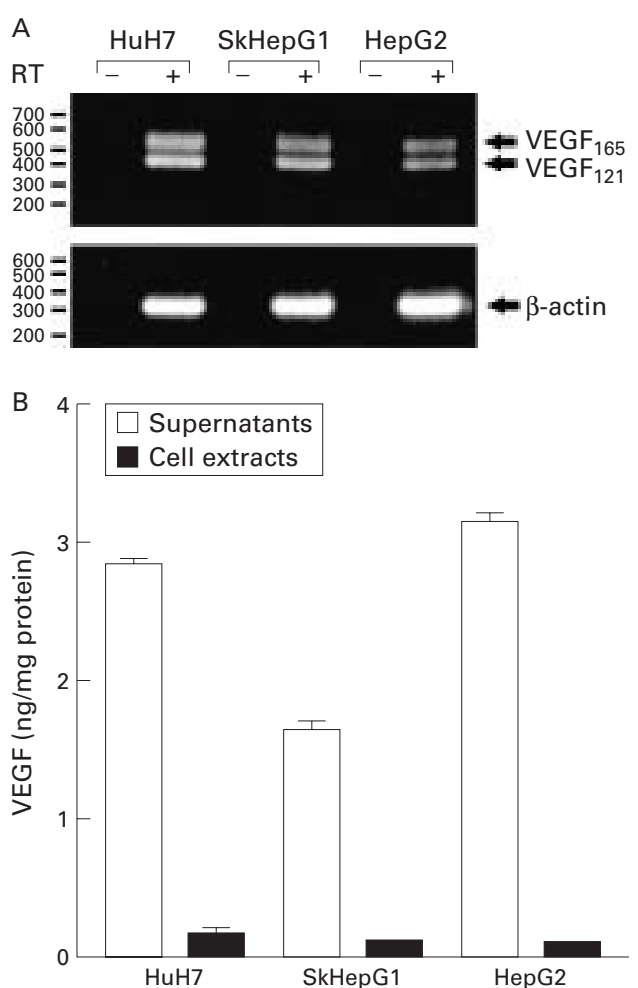

Figure 3 Expression of vascular endothelial growth factor (VEGF) in human hepatocellular carcinoma (HCC) cell lines. (A) Analysis of VEGF $m R N A$ transcripts by reverse transcription-polymerase chain reaction (RT-PCR) using primers specific for all known isoforms. The size of the indicated bands of 403 and 535 bp was determined by a $100 \mathrm{bp}$ ladder and correspond to $V E G F_{121}$ and $V E G F_{165}$ respectively. $R T-, P C R$ without reverse transcription. (B) Expression of VEGF protein: a VEGF specific ELISA was used to determine VEGF concentrations in supernatants and cell extracts of the indicated cell lines and normalised to protein content. Mean (SEM) of three experiments, each performed in triplicate.

hybridisation signal for VEGF in 13 of 15 carcinomas (87\%). VEGF mRNA was located over tumour cells throughout the tumour but specific enhancement of the hybridisation signal was observed in the areas directly adjacent to necrotic foci (fig 1B). VEGF hybridisation signals were also present in hepatocytes of cirrhotic liver in 11 of $15(73 \%)$ cases and in normal liver (data not shown) but VEGF mRNA expression was considerably less intense compared with HCC specimens. Additionally, we observed specific VEGF mRNA expression in epithelial cells of bile ducts (fig 1D). Results of in situ hybridisation are summarised in table 2. A similar expression pattern for VEGF protein was observed after immunostaining with a polyclonal antibody specific for human VEGF (fig 1A, C). To confirm the specificity of the VEGF expression pattern observed by in situ hybridisation we analysed a sense cRNA in parallel, which did not reveal any significant hybridisation signal (data not shown).

EXPRESSION OF VEGF RECEPTORS IN HUMAN HCC AND CIRRHOTIC LIVER

Using a monoclonal antibody against the endothelial cell specific antigen CD31, we detected a considerable number of blood vessels surrounding tumour cells (fig $2 \mathrm{~A}$ ). In situ hybridisation using ${ }^{35} \mathrm{~S}$ labelled cRNA probes specific for human KDR/flk-1 and flt-1 revealed that both VEGF receptors were expressed in tumour endothelial cells. KDR/ flk-1 mRNA was detected in 13 of $15(85 \%)$ and flt- 1 in eight of 15 (53\%) HCCs (fig 2C, $2 \mathrm{E})$. In contrast, hybridisation signals for $\mathrm{KDR} / \mathrm{flk}-1$ were detected in only six of 15 cirrhotic tissue specimens and no hybridisation signal was detected in liver cirrhosis after hybridisation with the human flt-1 antisense probe (data not shown). To confirm the specificity of the hybridisation signal, tissue sections were processed with a sense cRNA in parallel, which did not reveal any significant hybridisation (fig 2D, F). Results of in situ hybridisation data are summarised in table 2 . Immunostaining with polyclonal antibodies specific for human KDR/flk-1 and flt-1 confirmed the expression pattern observed using in situ hybridisation.

EXPRESSION OF VEGF IN HUMAN HCC CELL LINES Pronounced upregulation of VEGF in HCC tumour cells directly surrounding the presumably hypoxic necrotic areas suggests hypoxia as
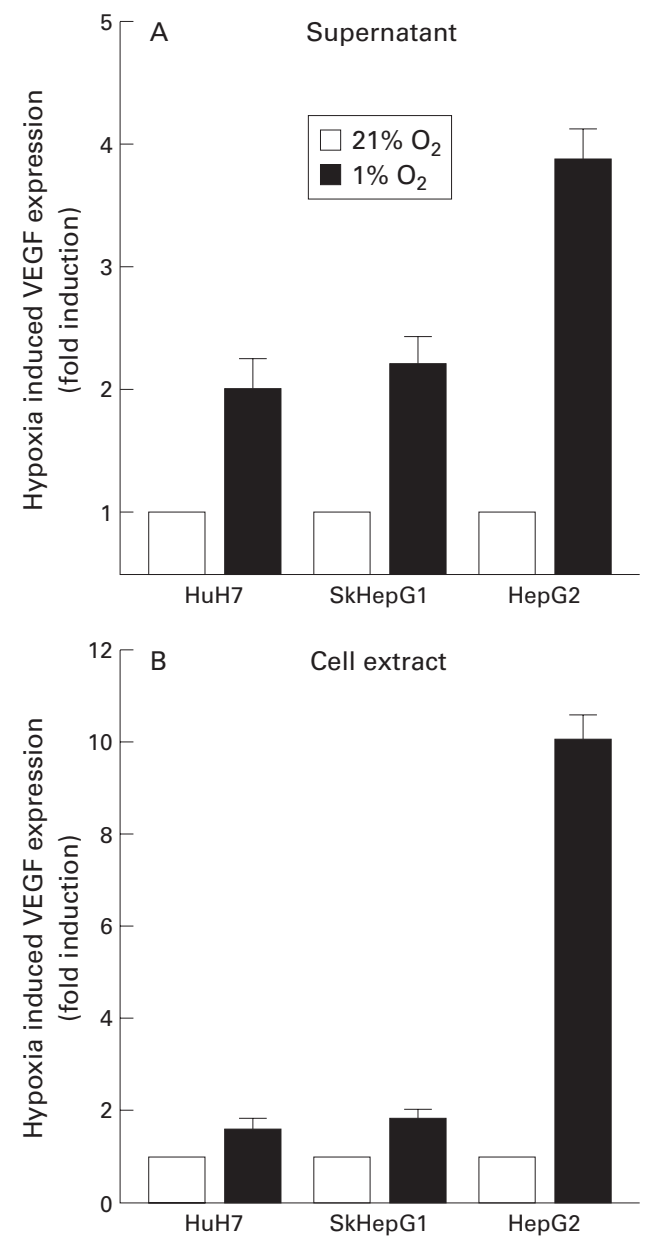

Figure 4 Hypoxia mediated induction of vascular endothelial growth factor (VEGF) protein in human hepatocellular carcinoma (HCC) cell lines. VEGF specific ELISA was used to determine VEGF concentrations in supernatants $(A)$ and cell extracts $(B)$ of the indicated cell lines incubated either under normoxic $\left(21 \% \mathrm{O}_{2}\right)$ or hypoxic $\left(1 \% \mathrm{O}_{2}\right)$ conditions for 16 hours and normalised to protein content. Mean (SEM) of three experiments, each performed in triplicate. 

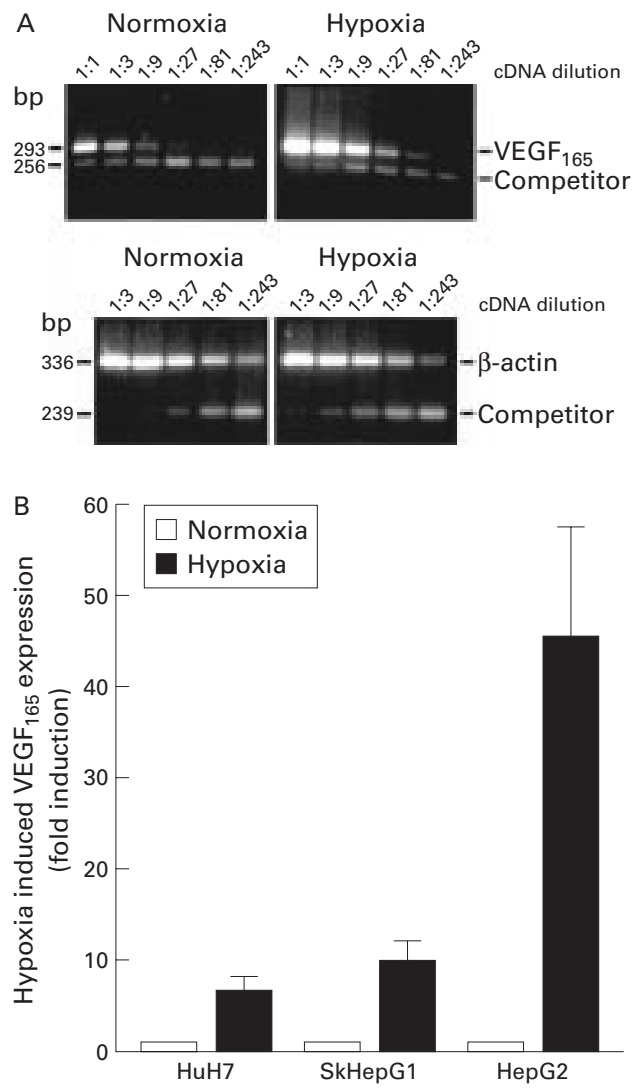

Figure 5 Effects of hypoxia on vascular endothelial growth factor (VEGF) $m R N A$ expression in hepatocellular carcinoma (HCC) cell lines. VEGF $m R N A$ expression was measured by quantitative competitive reverse transcription-polymerase chain reaction (RT-PCR). Total $R N A$ was isolated from cells incubated for 16 hours under normoxic or hypoxic conditions and subjected to RT. A constant amount of competitor and threefold serial dilutions of cDNAs were used as templates for PCR using VEGF ${ }_{165}$ or $\beta$-actin specific primers. (A) Representative image of ethidium bromide stained gels for HepG2 cells. (B)

Quantitative analysis. VEGF ${ }_{165}$ expression was calculated as the molar ratio of VEGF to $\beta$-actin copies. Mean (SEM) values of three independent experiments determined as fold induction by hypoxia.

an important inducer of VEGF expression in human HCC in vivo. To further study hypoxia mediated regulation of VEGF gene expression we first analysed expression of VEGF in three human HCC cell lines in vitro. RT-PCR analysis using oligonucleotide primers designed to amplify all five known splice variants of VEGF revealed that two VEGF mRNA splice forms were expressed in all cell lines. The amplified bands of 403 and $535 \mathrm{bp}$ corresponded to $m R N A s$ for $V_{E G F}$ and $V_{121}$ EFF ${ }_{165}$, respectively (fig 3A). In contrast, no PCR amplicons corresponding to $\mathrm{VEGF}_{145}, \mathrm{VEGF}_{189}$, or $\mathrm{VEGF}_{206}$ mRNA transcripts were detected. Using a human VEGF specific ELISA, which recognises the $\mathrm{VEGF}_{165}$ and $\mathrm{VEGF}_{121}$ splicing variants, we also detected VEGF in supernatants and cell extracts of all three tested cell lines. As VEGF is constitutively secreted, VEGF abundance was higher in supernatants compared with cell extracts. VEGF concentrations obtained from three independent experiments were as follows: $2.9(0.03) \mathrm{ng} / \mathrm{mg}$ protein in HuH7; 1.7 (0.06) in SkHepG1; and 3.2 (0.07) in HepG2 (fig 3B).
HYPOXIA INDUCES VEGF EXPRESSION IN HUMAN HCC CELL LINES

To investigate if hypoxia induces changes in VEGF protein levels, HCC cells were incubated under normoxic $\left(21 \% \mathrm{O}_{2}\right)$ or hypoxic $\left(1 \% \mathrm{O}_{2}\right)$ conditions for 16 hours and VEGF concentrations in supernatants and cell extracts were measured using ELISA. In response to hypoxia, the level of secreted as well as cellular VEGF consistently increased in all cell lines. However, the extent of induction varied from approximately twofold in $\mathrm{HuH} 7$ and SkHepG1 cells to $4-10$-fold in HepG2 cells (fig 4A, 4B).

MOLECULAR MECHANISM OF HYPOXIA INDUCED VEGF EXPRESSION

To further characterise the underlying mechanisms for VEGF induction by hypoxia, we next investigated hypoxia mediated induction of VEGF mRNA concentrations using competitive quantitative RT-PCR. Total RNA was isolated from cells after normoxic or hypoxic incubation for 16 hours and subjected to quantitative competitive RT-PCR as described above. As shown in fig 5, VEGF mRNA expression was increased under hypoxic conditions in all cell lines. In agreement with VEGF protein determinations (fig 4), the most pronounced response to hypoxia was observed in HepG2 cells. The fold inductions of VEGF mRNA determined from three independent experiments were as follows: $6.7(1.5)$ in HuH7; 9.8 (2.3) in SkHepG1; and 45.5 (12.1) in HepG2 (fig 5B).

STABILISATION OF VEGF MRNA BY HYPOXIA IN HCC CELLS

To identify mechanisms responsible for the observed induction of VEGF mRNA steady state concentrations, we next investigated the effects of hypoxia on VEGF mRNA stability. For this purpose we used HepG2 cells as a representative cell system. Cells were cultured under normoxic or hypoxic conditions for 16 hours prior to addition of $150 \mu \mathrm{M}$ DRB to

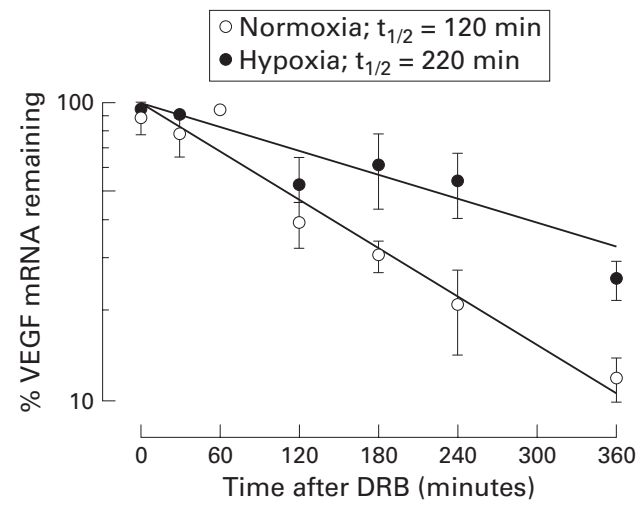

Figure 6 Hypoxia increased vascular endothelial growth factor (VEGF) $m$ RNA half life in HepG2 cells. Cells were incubated for 16 hours under normoxic or hypoxic conditions and subsequently incubated with $150 \mu \mathrm{M} \mathrm{DRB}$ to block transcription. Cells were harvested for RNA after $0,30,60,120,180,240$, and 360 minutes. VEGF mRNA was then determined by quantitative competitive reverse transcription-polymerase chain reaction as described in materials and methods. Mean (SEM) values of three independent experiments. 
block transcription. Cells were then harvested for RNA at $0,0.5,1,2,3,4$, and 6 hours. Quantification of $\mathrm{VEGF}_{165} \mathrm{mRNA}$ half life was then determined by quantitative competitive RT-PCR. Exposing HepG2 cells to 16 hours of hypoxia resulted in an increase in VEGF mRNA stability. VEGF mRNA half life was calculated to be 120 minutes under normoxic conditions which increased to 220 minutes under hypoxic conditions (fig 6).

VEGF 5' FLANKING SEQUENCES MEDIATE TRANSCRIPTIONAL RESPONSE TO HYPOXIA Although hypoxia significantly stabilised VEGF mRNA, this mechanism cannot fully account for the extent of the observed induction of VEGF mRNA concentration (approximately 46-fold higher than under normoxic conditions). Therefore, we next examined if hypoxia might also regulate VEGF gene transcription. For this purpose we tested a series of $5^{\prime}$ deletion constructs of a human VEGF promoter reporter construct for their responsiveness to hypoxia. The constructs, which ranged in their 5 ' ends from -2018 to -52 , were transiently transfected into HepG2 cells. The results shown in fig 7 demonstrate that the pLuc 2068 and the pLuc 1340 reporter constructs mediated a significant 9.4fold (1.8) and 11.3-fold (2.98) increase in luciferase activity in cells exposed to $1 \% \mathrm{O}_{2}$ compared with normoxic control cells $(\mathrm{p}<0.001 ; \mathrm{n}=4)$. The ability to respond to hypoxia decreased significantly as further $5^{\prime}$ flanking sequences were deleted. The most impressive reduction was associated with deletion of nucleotide sequences between -1286 and -789 . The sequences located between -789 and -52 mediated an approximately 2-3-fold increase in luciferase activity on hypoxia which did not reach statistical significance compared with normoxic controls. These results demonstrate that VEGF 5' flanking sequences mediate transcriptional responses to hypoxia in HepG2 cells and indicate
A

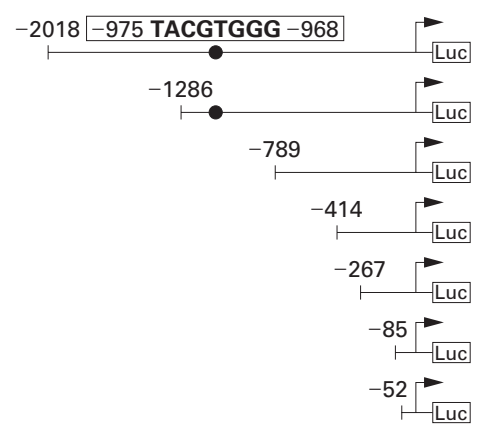

B Fold induction by hypoxia

$\begin{array}{lllllll}0.0 & 2.5 & 5.0 & 7.5 & 10.0 & 12.5 & 15.0\end{array}$

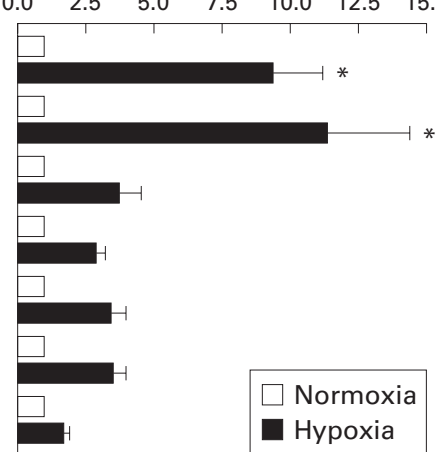

Figure 7 Effects of hypoxia on vascular endothelial growth factor (VEGF) gene transcription. (A) Schematic diagram of the VEGF promoter-Luc reporter constructs. The nucleotide sequence -2018 to +50 bp of the human VEGF gene promoter was cloned in front of a luciferase gene, and serial 5' deletion constructs were generated between positions -2018 and $-52 \mathrm{bp}$. The transcription start is indicated by an arrow. Potential consensus binding sites for HIF-1 are indicated $(\bullet)$. (B) Hypoxia mediated transactivation in HepG2 cells. HepG2 cells were transiently cotransfected with VEGF-Luc and $\beta$-gal plasmids and incubated for 16 hours with $21 \% \mathrm{O}_{2}$ or $1 \% \mathrm{O}_{2}$. Luciferase activity was determined and normalised for transfection efficiency. Mean (SEM) values of four independent experiments, each performed in triplicate, and determined as fold induction by hypoxia. ${ }^{\star S i g n i f i c a n t l y ~ d i f f e r e n t ~ f r o m ~ c o n t r o l ~}(p<0.001)$. a critical role of the -975 putative hypoxia inducible factor 1 (HIF-1) binding site for these effects.

\section{Discussion}

Induction of angiogenesis is a critical event during malignant transformation and contributes significantly to invasive local growth behaviour and metastatic potential. Human HCC is a highly vascularised tumour indicating that angiogenesis plays an important role in its tumour biology. In particular, VEGF and its receptors have been implicated in induction of tumour associated angiogenesis in HCC. Several earlier studies have demonstrated increased expression of VEGF in human HCC tissues, ${ }^{31-34} 37$ although little is currently known of the molecular mechanisms responsible for VEGF upregulation. Furthermore, expression of the biological target structures (for example, the VEGF receptor) in normal and malignant transformed human liver has not been investigated. Hence we aimed to evaluate the expression pattern of VEGF receptors in HCC tissues and the molecular events underlying VEGF upregulation.

Using immunohistochemistry and in situ hybridisation we found that a high percentage of human HCC samples expressed significant amounts of KDR/flk-1 (87\%) and flt-1 (53\%) in endothelial cells. In contrast, we observed positive signals for $\mathrm{KDR} / \mathrm{flk}-1$ in endothelial cells of cirrhotic liver in only six of 15 (40\%) tissue specimens and no expression of flt- 1 was detected in cirrhotic liver. This implicates de novo expression of both VEGF receptors in HCC compared with non-transformed liver. Therefore, concurrent upregulation of VEGF and its receptors observed in the current study appears to be a critical event in induction of angiogenesis on malignant transformation in human liver. This is supported by recent observations derived from an experimental murine model of HCC. According to that study, tumour growth induced by VEGF over expression was almost completely abolished by a specific KDR/flk-1 neutralising antibody. ${ }^{38}$ Clarification of the mechanisms underlying VEGF/VEGF receptor upregulation in vivo is therefore of great interest to improve our understanding of the pathophysiology involved in HCC associated angiogenesis.

In agreement with previous studies, ${ }^{31-34}{ }^{37}$ we demonstrated strong expression of VEGF in a large percentage of human HCC samples accompanied by a considerable number of blood vessels surrounding the tumour cells. Using immunohistochemistry and in situ hybridisation, we detected VEGF expression in tumour cells as well as in non-tumoral hepatocytes. However, VEGF expression was much stronger in tumour cells compared with hepatocytes in normal or cirrhotic liver. Interestingly, we also detected VEGF mRNA and protein expression in epithelial cells of bile ducts in all examined cases. The biological significance of VEGF in normal liver is poorly understood although VEGF expression in liver cirrhosis has been suggested to result from proinflammatory cytokines released by infil- 
trating lymphocytes. This hypothesis is supported by in vitro studies showing that tumour necrosis factor $\alpha$ and interleukin $1 \beta$ can increase VEGF secretion ${ }^{33}$. Furthermore, VEGF expression is known to be induced by insulin-like growth factor $\mathrm{II}^{39}$ which is highly expressed in cirrhotic liver and HCC tissues. ${ }^{40}$ Despite these observations, the molecular basis of VEGF over expression in HCC remains incompletely understood. In situ hybridisation analysis in the current study revealed a heterogeneous pattern of VEGF mRNA transcripts over HCC tumour cells with pronounced expression observed in tumour cells immediately adjacent and surrounding necrotic (presumably hypoxic) regions, suggesting that hypoxia may trigger angiogenesis via induction of perinecrotic VEGF expression (compare fig 1). Regions of low oxygen (hypoxia) and necrosis are common features of solid tumours and a marked elevation in VEGF expression in tumour cells around necrotic areas has been suggested in some neoplasms. ${ }^{22} 2541-44$

Based on our observation that hypoxia may play a central role in VEGF upregulation in HCC, we analysed hypoxia regulated VEGF gene expression in human HCC cell lines in more detail.

Using RT-PCR and VEGF specific ELISA, we found that all three cell lines expressed VEGF mRNA and protein. In agreement with previous studies, we observed that $\mathrm{VEGF}_{121}$ and $\mathrm{VEGF}_{165}$ were the predominantly expressed VEGF isoforms in human HCC cells. $^{31} 34$ These two isoforms share a common signal peptide which results in cellular secretion and detection in culture supernatants. Consequently, we first examined the effect of hypoxia on secreted and cellular VEGF protein. Incubation of human HCC cell lines under hypoxic conditions resulted in a pronounced increase in VEGF protein concentration in all three cell lines. The mechanisms by which oxygen tension controls VEGF expression is not fully understood. Several lines of evidence indicate that enhanced VEGF expression in response to hypoxia is due to transcriptional activation ${ }^{45}$ as well as mRNA stabilisation. ${ }^{47-50}$ In addition, an internal ribosome entry site ensures efficient translation of VEGF mRNA, even under hypoxic conditions. ${ }^{51}$ To further characterise the underlying mechanisms responsible for VEGF stimulation by hypoxia, we investigated the effects on VEGF mRNA expression. We observed a substantial increase in VEGF mRNA concentrations suggesting that hypoxia mediated upregulation of VEGF occurs mainly at the pretranslational level. To further elucidate the molecular mechanisms responsible for hypoxia mediated induction of VEGF gene expression in HCC cells, we performed mRNA half life experiments and tested a series of 5 ' deletion constructs of human VEGF promoter reporter constructs for their ability to mediate transcriptional responses to hypoxia. We observed that at least two distinct molecular mechanisms contribute to the observed increase in VEGF mRNA concentration in HepG2 cells under hypoxic conditions. Stabilisation of VEGF
mRNA after 16 hours of hypoxic treatment was found to contribute to hypoxia induced VEGF mRNA expression, demonstrating a nearly doubling of VEGF mRNA stability in HepG2 cells. Induction of hypoxia mediated VEGF mRNA stabilisation observed for HCC tumour cells was similar to that previously observed for human glioblastoma, ${ }^{47}$ human melanoma, ${ }^{49}$ and for rat phaeochromocytoma (PC12). ${ }^{50}$ Stabilisation of VEGF mRNA is thought to be mediated, at least in part, by hypoxia augmented binding of proteins to its 3 ' untranslated region. Recently, a single 125 bp AU rich element in the 3' untranslated region of human VEGF mRNA has been identified that forms hypoxia inducible RNA binding complexes with a series of hypoxia induced proteins in human melanoma cells. ${ }^{51}$ Whether these mechanisms are also operative in HCC is currently under investigation.

Stabilisation of VEGF mRNA by hypoxia could not fully account for the extent of the observed induction of VEGF mRNA concentrations. To investigate if transcriptional mechanisms are involved in hypoxia mediated upregulation of VEGF mRNA steady state concentrations, we tested the $5^{\prime}$ flanking region of the human VEGF gene for hypoxia responsive elements by transient transfection with a series of deletion constructs. The highest responsiveness to hypoxia was observed with reporter plasmids containing the VEGF promoter regions -2018 to +50 and -1286 to +50 . Hypoxia mediated induction of luciferase activity was approximately 10 -fold and was significantly reduced to threefold by deletion of the sequences between -1286 and -789 . An additional but less marked loss of induction occurred with deletion of the promoter region -85 to -52 . Transcriptional upregulation of VEGF in response to hypoxia appears to be mediated mainly by the hypoxia regulated transcription factor HIF-1 which accumulates under hypoxic conditions and activates VEGF gene transcription through binding to specific promoter sequences. ${ }^{45} 46$ 51-53 Significant reduction of luciferase activity after deletion of the sequence between -1286 and -789 indicates a substantial contribution of the -975 putative HIF-1 binding site to transcriptional activation of the VEGF gene under hypoxic conditions. Nucleotide sequences located between -789 and +50 still appeared somewhat responsive to hypoxia but these increases failed to reach statistical significance compared with normoxic controls.

In summary, concurrent upregulation of VEGF and its receptors suggests that VEGF may play an important role in tumour associated angiogenesis in HCC. Furthermore, hypoxia seems to be an important driving force for angiogenesis during tumour progression in human HCC through upregulation of VEGF gene expression by at least two distinct molecular mechanisms: activation of VEGF gene transcription and an increase in VEGF mRNA stability.

This work was supported by a grant from Deutsche Forschungsgemeinschaft (Ro 674/13-1) and Wilhelm Sander Stiftung. 
1 Folkman $\mathrm{J}$, Watson $\mathrm{K}$, Ingber $\mathrm{D}$, et al. Induction of angiogenesis during the transition from hyperplasia to neo-

2 Folkman J. Angiogenesis in cancer, vascular, rheumatoid and other disease. Nat Med 1995;1:27-31.

3 Folkman J. Seminars in medicine of the Beth Israel Hospital, Boston. Clinical applications of research on angiogenesis. N Engl f Med 1995;333:1757-63.

4 Hanahan D, Folkman J. Patterns and emerging mechanisms of the angiogenic switch during tumourigenesis. Cell 1996; 86:353-64.

5 Ferrara N, Heinsohn H, Walder CE, et al. The regulation of blood vessel growth by vascular endothelial growth factor. Ann NY Acad Sci 1995;752:246-56.

6 Ferrara N. The role of vascular endothelial growth factor in pathological angiogenesis. Breast Cancer Res Treat 1995;36: 127-37.

7 Kolch W, Martiny-Baron G, Kieser A, et al. Regulation of the expression of the VEGF/VPS and its receptors: role in tumour angiogenesis. Breast Cancer Res Treat 1995;36:13955.

8 Leung DW, Cachianes G, Kuang WJ, et al. Vascular endothelial growth factor is a secreted angiogenic mitogen nce $1989 ; 246: 1306-9$.

9 Houck KA, Ferrara N, Winer J, et al. The vascular endothelial growth factor family: identification of a fourth molecular species and characterization of alternative splicing of RNA. Mol Endocrinol 1991;5:1806-14.

10 Tischer E, Mitchell R, Hartmann T, et al. The human gene for vascular endothelial growth factor. $7 \mathrm{Biol}$ Chem 1991;266:11947-54.

11 Poltorak Z, Cohen T, Sivan R, et al. $\mathrm{VEGF}_{145}$, a secreted vascular endothelial growth factor isoform that binds to extracellular matrix. F Biol Chem 1997;272:7151-8.

12 Houck KA, Leung DW, Rowland AM, et al. Dual regulation of vascular endothelial growth factor bioavailability by genetic and proteolytic mechanisms. F Biol Chem 1992;267: 26031-7.

13 De Vries C, Escobedo JA, Ueno H, et al. The fms-like tyrosine kinase, a receptor for vascular endothelial growth factor. Science 1992;255:989-91.

14 Terman BI, Dougher-Vermazen MD, Carrion ME, et al. Identification of the KDR tyrosine kinase as a receptor for vascular endothelial cell growth factor. Biochem Biophys Res
Commun 1992;187:1579-86.

15 Matthews W, Jordan CT, Gavin M, et al. A receptor tyrosine kinase cDNA isolated from a population of enriched primitive hematopoetic cells and exhibiting close genetic linkage to c-kit. Proc Natl Acad Sci USA 1991;88:9026-30.

16 Quinn T, Peters KG, deVries C, et al. Fetal liver kinase 1 is a receptor for vascular endothelial growth factor and is selectively expressed in vascular endothelium. Proc Nat Acad Sci USA 1993;90:7533-7.

17 Barleon B, Hauser S, Schollmann C, et al. Differentia expression of the two VEGF receptors flt and KDR in placenta and vascular endothelial cells. $\mathcal{f}$ Cell Biochem 1994;54:56-66.

18 Breier G, Clauss M, Risau W. Coordinate expression of vascular endothelial growth factor receptor-1 (flt-1) and its ligand suggests a paracrine regulation of murine vascular ligand suggests a paracrine regulation of
development. Dev Dyn 1995;204:228-39.

19 Millauer B, Wizigmann-Voos S, Schnurch H, et al. High affinity VEGF binding and developmental expression suggest Flk-1 as a major regulator of vasculogenesis and angiogenesis. Cell 1993;72:835-46.

20 Waltenberger J, Claesson-Welsh L, Siegbahn A, et al. Different signal transduction properties of KDR and Flt-1, two receptors for vascular endothelial growth factor. $\mathcal{F}$ Biol Chem 1994;269:26988-95.

21 Wheeler-Jones C, Abu-Ghazaleh R, Cospedal R, et al. Vascular endothelial growth factor stimulates prostacyclin production and activation of cytosolic phospholipase A2 in endothelial cells via $\mathrm{p} 42 / \mathrm{p} 44$ mitogen-activated protein kinase. FEBS Lett 1997;420:28-32.

22 Brown LF, Berse B, Jackman RW, et al. Expression of vascular permeability factor (vascular endothelial growth factor) and its receptors in adenocarcinomas of the gastrointestinal tract. Cancer Res 1993;53:4727-35.

23 Brown LF, Berse B, Jackman RW, et al. Increased expression of vascular permeability factor (vascular endothelial growth factor) and its receptors in kidney and bladder carcinomas. Am F Pathol 1993;143:1255-62.

24 Takahashi Y, Kitadai Y, Bucana CD, et al. Expression of vascular endothelial growth factor and its receptor, KDR, correlates with vascularity, metastasis, and proliferation of human colon cancer. Cancer Res 1995;55:3964-8.

25 Plate KH, Breier G, Weich HA, et al. Vascular endothelial growth factor is a potential tumour angiogenesis factor in human gliomas in vivo. Nature 1992;359:845-8.

26 Kondo S, Asano M, Suzuki H. Significance of vascular endothelial growth factor/vascular permeability factor for solid tumour growth, and its inhibition by the antibody. Biochem Biophys Res Commun 1993;194:1234-41.

$27 \mathrm{Kim} \mathrm{KJ}$, Li B, Winer J, et al. Inhibition of vascular endothelial growth factor-induced angiogenesis suppresses tumour growth in vivo. Nature 1993;362:841-44.
28 Millauer B, Shawver LK, Plate KH, et al. Glioblastoma growth inhibited in vivo by a dominant-negative Flk-1 growth inhibited in vivo by a
mutant. Nature 1994;367:576-9.

29 Millauer B, Longhi MP, Plate $\mathrm{KH}$, et al. Dominant-negative inhibition of Flk-1 suppresses the growth of many tumour types in vivo. Cancer Res 1996;56:1615-20.

30 Simonetti RG, Camma C, Fiorello F, et al. Hepatocellular carcinoma. A worldwide problem and the major risk factors. Dig Dis Sci 1991;36:962-72.

31 Suzuki K, Hayaski N, Mijamoto Y, et al. Expression of vascular permeability factor/vascular endothelial growth factor in human hepatocellular carcinoma. Cancer Res 1996;65: 3004-9.

32 Miura H, Miyazaki T, Kuroda M, et al. Increased expression of vascular endothelial growth factor in human hepatocellular carcinoma. F Hepatol 1997;27:854-61.

33 Yamaguchi R, Yano H, Iemura A, et al. Expression of vascular endothelial growth factor in human hepatocellular carcinoma. Hepatology 1998;28:68-77.

34 Torimura $T$, Sata $M$, Ueno $T$, et al. Increased expression of vascular endothelial growth factor is associated with tumour progression in hepatocellular carcinoma. Hum Pathol 1998;29:986-91.

35 Matthes K, Kaiser A, Stier U, et al. Glucocorticoid receptor gene expression in the exocrine and endocrine rat pancreas. Endocrinology 1994;135:476-9.

36 Jin CF, Mata M, Fink DJ. Rapid construction of deleted DNA fragments for use as internal standards in competitive PCR. PCR Methods Appl 1994;3:252-5.

37 Mise M, Arii S, Higashizuji $\mathrm{H}$, et al. Clinical signification of vascular endothelial growth factor and basic fibroblast growth factor gene expression in liver tumour. Hepatology 1996;23:455-64

38 Yoshiji H, Kuriyama S, Hicklin DJ, et al. KDR/flk-1 is a major regulator of vascular endothelial growth factorinduced tumour development and angiogenesis in murine hapatocellular carcinoma cells. Hepatology 1999;30:1179-

$39 \mathrm{Kim} \mathrm{KW}$, Bae SK, Lee OH, et al. Insulin-like growth factor II induced by hypoxia may contribute to angiogenesis of human HCC. Cancer Res 1998;58:348-51.

40 Park BC, Huh MH, Seo JH. Differential expression of transforming growth factor alpha and insulin-like growth factor II in chronic active hepatitis B, cirrhosis and hepatocellular carcinoma. $\mathcal{F}$ Hepatol 1995;22:286-94.

41 Plate $\mathrm{KH}$, Breier G, Weich HA, et al. Vascular endothelial growth factor and glioma angiogenesis: coordinate induction of VEGF receptors, distribution of VEGF protein and possible in vivo regulatory mechanisms. Int $\mathcal{F}$ Cancer 1994; 59:520-9.

42 Brown LF, Berse B, Jackman RW, et al. Expression of vascular permeability factor (vascular endothelial growth factor) and its receptors in breast cancer. Hum Pathol 1995;26:8691 .

43 Takahashi A, Sasaki H, Kim SJ, et al. Markedly increased amounts of messenger RNAs for vascular endothelial growth factor and placenta growth factor in renal cell carcinoma associated with angiogenesis. Cancer Res 1994;54: 4233-7.

44 Shweiki D, Itin A, Soffer D, et al. Vascular endothelial growth factor induced by hypoxia may mediate hypoxianitiated angiogenesis. Nature 1992;359:843-5.

45 Levy AP, Levy NS, Wegner S, et al. Transcriptional regulation of the rat vascular endothelial growth factor gene by hypoxia. F Biol Chem 1995;270:13333-40.

46 Forsythe JA, Jiang BH, Iyer NV, et al. Activation of vascular endothelial growth factor gene transcription by hypoxiainducible factor 1. Mol Cell Biol 1996;16:4604-13.

47 Ikeda E, Achen MG, Breier G, et al. Hypoxia-induced transcriptional activation and increased mRNA stability of vascular endothelial growth factor in C6 glioma cells. 7 Biol Chem 1995;270:19761-6.

48 Levy NS, Chung S, Furneaux H, et al. Hypoxic stabilization of vascular endothelial growth factor mRNA by the RNAbinding protein HuR. F Biol Chem 1998; 273:6417-23.

49 Claffey KP, Shih SC, Mullen A, et al. Identification of a human VPF/VEGF 3' untranslated region mediating hypoxia-induced mRNA stability. Mol Biol Cell 1998;9: 469-81.

50 Levy AP, Levy NS, Goldberg MA. Post-transcriptional regulation of vascular endothelial growth factor by hypoxia. fBiol Chem 1996;271:2746-53.

51 Stein I, Itin A, Einat P, et al. Translation of vascular endothelial growth factor mRNA by internal ribosome entry: implication for translation under hypoxia. Mol Cell Biol 1998;18:3112-19.

52 Huang LE, Arany Z, Livingston DM, et al. Activation of hypoxia-inducible transcription factor depends primarily upon redox-sensitive stabilization of its $\alpha$-subunit. $\mathcal{F} \mathrm{Biol}$ Chem 1996;271:32253-9.

53 Salceda S, Caro J. Hypoxia-inducible factor 1a (HIF1- $\alpha$ ) protein is rapidly degraded by the ubiquitin-proteasome system under normoxic conditions. F Biol Chem 1997;272: $22642-7$. 